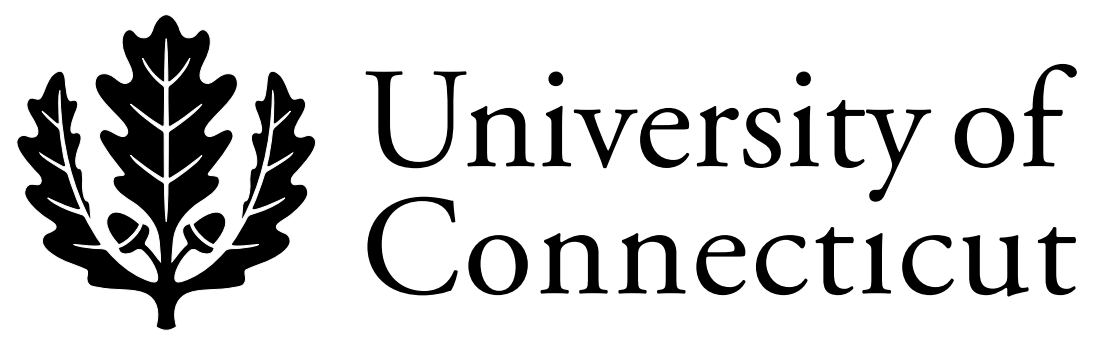

Department of Economics Working Paper Series

Do Exposure Suits Produce a Race to File? An Economic Analysis of a Tort for Risk

Thomas J. Miceli

University of Connecticut

Kathleen Segerson

University of Connecticut

Working Paper 2002-42

October 2001, revised February 2002

341 Mansfield Road, Unit 1063

Storrs, CT 06269-1063

Phone: (860) 486-3022

Fax: (860) 486-4463

http://www.econ.uconn.edu/ 


\begin{abstract}
Conventional tort law does not allow victims of exposure to a toxic substance to seek compensation until they develop actual symptoms of illness. This may effectively bar recovery because at the time the illness arises, injurers may be judgment proof. One possible response is to allow a tort for risk that allows victims to seek expected damages at the time of exposure. However, critics charge that this could create a race to file wherein victims rush to file suit to ensure that they will get a share of the injurers limited assets. We show that such a race may or may not occur in equilibrium, and that when it does occur, not all victims choose to file at exposure if bankruptcy is an inevitable result. If bankruptcy is not inevitable, it is possible that a tort for risk will trigger bankruptcy, although a no-bankruptcy equilibrium always exists and Paretodominates the bankruptcy equilibrium. We examine the consequences of the various tort-for-risk equilibria on the compensation of exposure victims, litigation costs, and injurer care.
\end{abstract}

Journal of Economic Literature Classification: K13, K32, K41 


\section{Do Exposure Suits Produce a "Race to File"? An Economic Analysis of a Tort for Risk}

\section{Introduction}

Many environmental accidents involve exposure to a hazardous substance that creates the possibility, but not the certainty, of a future illness. Examples include accidental chemical releases (such as the one that occurred in Bhopal, India in 1984 ${ }^{1}$ ), and nuclear accidents (such as Three Mile Island and Chernobyl). ${ }^{2}$ Normally, victims of exposure are barred from suing for damages until the time when an illness actually develops. ${ }^{3}$ However, some scholars have argued that these individuals should have the option of suing for expected damages at the time of exposure. ${ }^{4}$ This approach essentially views the exposure itself as a tort (what we call a "tort for risk" or a "tort for exposure"),

\footnotetext{
${ }^{1}$ For a discussion of the Bhopal accident, see Fischer (1996).

${ }^{2}$ Another related example is prolonged exposure to hazardous substances such as asbestos. Many such exposures occur in the workplace. This introduces two complications not considered in this paper: (1) the contractual relationship between the injurer and victim, and (2) the possibility of partial recovery under workers' compensation. We consider only "third party" accidents, where the victims have no contractual relationship with the injurer. Nonetheless, even in the case of asbestos, since workers' compensation is a system of partial liability, asbestos victims have sought recovery from asbestos manufacturers, with whom they have no direct contractual relationship. The model in this paper is relevant to this dimension of the asbestos problem.

${ }^{3}$ In some jurisdictions, even in the absence of a physical manifestation of exposure-related illness, victims are allowed to sue for emotional distress and/or medical monitoring expenses (Valk, 1995). In this paper, we abstract from issues regarding interim damages for emotional distress or medical monitoring and focus instead on the possibility that the exposure victim will ultimately contract an exposure-related illness. For a discussion of alternative liability rules in a tort-for-risk model with medical monitoring, see Miceli and Segerson (2001) and Bathgate (2001).

${ }^{4}$ Advocates of allowing a tort for risk include Chapin (1993), Landes and Posner (1984), Love (1996), Miller (1998), Note (1998), Rosen (1992), and Robinson (1995). Rose-Ackerman (1989) proposes a similar remedy, what she calls "ex ante suits", when the actions of one party increase the risk of direct monetary losses for another party, as for example, when one landowner builds a dam that increases the risk of flooding that would destroy the crops of downstream owners. For related discussions, see also Hamrick (1998), McDonnell (1997), and Rosenberg (1984).
} 
while under the conventional rule a tort is not deemed to have occurred unless the victim actually contracts the disease. ${ }^{5}$

Several previous authors have identified tradeoffs involved in allowing a tort for risk (see references in footnote 4). For example, some have argued that the number of cases, and hence litigation costs, would increase if a tort for risk were allowed, possibly "by several orders of magnitude" (Robinson, 1985: p. 796). In this sense, allowing a tort for risk would increase social costs. ${ }^{6}$ However, advocates suggest an offsetting deterrence benefit. In many toxic tort contexts, there is a long latency period between the time of exposure and the time a resulting disease is manifested. As a result, disallowing suits for exposure could actually bar victims from receiving any compensation if the injurer is insolvent or judgment-proof at the time the disease is contracted, ${ }^{7}$ or if the victim cannot establish a causal connection between her illness and the injurer's actions (Shavell, 1985). This affects not only the extent of victim compensation but also the injurer's incentive to invest in deterrence. Thus, the conventional wisdom is that allowing a tort for risk generates a benefit from increased deterrence that must be balanced against the cost from increased litigation.

\footnotetext{
${ }^{5}$ See, e.g., Keeton, et al. (1984), § 30, p. 165.

${ }^{6}$ In addition, some have argued that, if recovery is allowed for a tort for risk and then the individual never contracts the disease, the recovery constitutes a windfall for that individual. Conversely, since under a tort for risk recovery would be based on expected damages (rather than realized damages), individuals who eventually contract the disease would be undercompensated. Note, however, that victims who received payment at the time of exposure based on expected damages could presumably use their awards to purchase insurance that would provide full compensation if the disease is eventually contracted, thereby eliminating both over- and under-compensation (Robinson, 1985).

${ }^{7}$ See Ringleb and Wiggins (1990) for empirical evidence regarding long-term hazards and judgment-proof firms.
} 
The preceding conventional wisdom is based on an assumption that the risk of injurer insolvency is exogenous, i.e., driven by factors unrelated to liability. ${ }^{8}$ In many toxic tort contexts, however, the potential liability is sufficiently high that the liability itself could trigger bankruptcy (what we term "endogenous" bankruptcy). This second class of bankruptcy cases can arise when the expected damages plus litigation costs resulting from an exposure event exceed the injurer's assets. A well-known example is the bankruptcy of Johns-Manville Sales Corporation, which was triggered by the costs associated with asbestos litigation (Note, 1983). If victims fear that the injurer will be bankrupted by liability, there is the potential for a "race to file" under which victims have an incentive to file early in an effort to secure some portion of the injurer's limited assets. The question then is whether allowing suits at the time of exposure (a "tort for risk") would generate or exacerbate a race to file, and what implications it would have for total litigation costs and deterrence.

In this paper, we present an economic model of a tort-for-risk rule in a context where litigation is costly and injurers have limited assets. We first use the model to examine the impact of allowing a tort for risk on the victims' incentives to file suit. This allows us to examine whether allowing a tort for risk would in fact lead to a "race to file." Previous models of the impact of bankruptcy (e.g., Shavell 1986; Beard 1990; Larson 1996) do not consider the potential "competition" among victims for the injurer's assets. Modeling this competition allows us not only to examine the potential for a race to file but also to determine how the injurer's limited assets are ultimately apportioned. Our

\footnotetext{
${ }^{8}$ See Miceli and Segerson (2000) for a model demonstrating this tradeoff when the risk of insolvency is exogenous.
} 
results suggest that allowing a tort for risk would essentially establish a new priority rule for claims on the injurer's assets.

Second, we use our model to ask whether allowing a tort for risk could trigger bankruptcy even if, in the absence of a tort for risk, the liability associated with actual illnesses would not have done so. In this latter case, we show that, even if a tort for risk is allowed, an equilibrium under which all victims wait to sue, and bankruptcy does not occur, always exists. Thus, in such cases allowing a tort for risk will not necessarily trigger bankruptcy. However, we cannot rule out the possibility of other equilibria under which the tort for risk does trigger a race to file that leads to bankruptcy. Nonetheless, the equilibrium with no race is Pareto dominant in the sense that all victims are better off.

Finally, given the victims' incentives to sue, we use the model to examine whether the standard tradeoff between litigation costs and deterrence that arises in the context of exogenous bankruptcy exists when insolvency is triggered by liability. We show that such a tradeoff does not necessarily exist in this case.

The paper is organized as follows. Section 2 presents the general setup of the model. Section 3 then examines the decision of exposure victims of whether to file suit at exposure or to wait until they actually develop an illness. The question is whether exposure suits, if allowed, would produce a race to file that bankrupts injurers and leaves some victims uncompensated. Finally, Section 4 considers the impact of exposure suits on the expected number of suits and on injurer care. Section 5 offers concluding comments.

\section{The General Model}


In this section, we present the basic structure of the model. The model has three periods, a single injurer, and a population of victims, all of whom are risk-neutral. ${ }^{9}$ In the initial period $(\mathrm{t}=0)$, the injurer chooses a dollar investment in care, $x$, which determines the probability of exposure, $p(x)$, where $p^{\prime}<0$ and $p^{\prime \prime}>0$. In the next period $(\mathrm{t}=1)$, an exposure occurs with probability $p(x)$. If an exposure occurs, in the final period $(\mathrm{t}=2)$ an exposure victim will become ill and incur damages of $D$ dollars with probability $q$, and suffer no illness (and hence no damages) with probability 1-q. We assume that all victims suffer the same loss in the event of illness. However, we allow $q$ to vary across victims. This could reflect variations in the length or intensity of exposure. ${ }^{10}$ For example, some victims might be exposed for a longer period of time, or were in closer proximity to an accidental release of the hazardous substance, and hence were exposed to a larger quantity of the substance. The distribution of $q$ across the population of victims is given by $f(q)$.

For simplicity, we assume that neither $D$ nor $q$ depends on $x .{ }^{11}$ For example, we suppose that $x$ affects the probability that the victim is exposed to a carcinogen, but does not affect either the likelihood that she will contract the disease (given exposure), or the dollar loss that results. In the absence of bankruptcy, exposure victims who wait until they sustain actual damages before filing will get a net return equal to their losses, $D$, less

\footnotetext{
${ }^{9}$ We assume that there is no contractual relationship between the injurer and the victim, e.g., the victims are not employees or customers of the injurer. Thus, there is no possibility of shifting costs between the injurer and victim through adjustments in the contract terms. For a discussion of this possibility, see Landes and Posner (1985).

${ }^{10}$ This probability could also vary with an individual's susceptibility. However, this type of variation would be very difficult for a court to measure.

${ }^{11} \mathrm{We}$ also ignore the possibility that between the time of exposure and illness a victim could invest in medical monitoring, which could affect either $D$ or $q$. For a model of medical monitoring, see Miceli and Segerson (forthcoming).
} 
the costs of filing suit, $c_{v}{ }^{12} \mathrm{We}$ assume that $D>c_{v}$, so that filing suit if and when the illness arises would be profitable for all illness victims who expect to recover their full damages. We also abstract from the specific length of time it takes for the loss to arise, and we ignore discounting. These assumptions keep the model simple without affecting the qualitative nature of the results. In addition, we assume throughout that the liability rule in place is strict liability.

The economic problems in the above model are: (1) the injurer's choice of a level of precaution, and (2) the victim's decision of whether to file a suit for damages, and more importantly, when to file, assuming existence of a tort for risk. If a tort for risk is allowed, an exposure victim can file at the time of exposure $(t=1)$ or wait to file if and when damages occur $(\mathrm{t}=2)$. In discussing the victim's filing decision, we take the injurer's prior choice of precaution as given.

\section{Incentives to Sue and the Race to File}

In deciding whether to file suit at the time of exposure or illness, each victim will compare the net return from filing at exposure to the net return she would expect to receive if she waited and filed instead at the time of illness (if it occurs). In making this comparison, the victim faces the following tradeoff. If she files at the time of exposure, she will incur litigation costs with certainty, whereas if she waits until illness, she will incur these costs only with probability $q$ (the probability she will actually become ill and hence sue). Thus, the advantage of waiting is the reduction in expected litigation costs. The cost, on the other hand, is the potential reduction in the damage award if the injurer's

\footnotetext{
${ }^{12}$ We assume throughout that victims always win suits that are filed. We thus abstract from the potentially difficult problem of proving causation. For a general treatment of the causation issue, see Shavell (1985).
} 
assets have been reduced or depleted by other (i.e., earlier) suits. Of course, this cost depends on the filing decisions of other victims, i.e., the number of other victims who choose to file at exposure. We are thus interested in determining a Nash equilibrium under which each victim makes the filing decision that maximizes her expected return, given the filing decisions of all other victims.

Since an increase in $q$ reduces the expected savings in litigation costs from waiting to file, we conjecture equilibria under which there is some threshold $\widetilde{q}$ such that all victims with $q>\widetilde{q}$ file at the time of exposure while all victims with $q \leq \widetilde{q}$ wait until the time of illness to file. The task is to determine the equilibrium $\widetilde{q}$ in this context. Note that $\widetilde{q}=0$ would imply a complete race to file, under which all exposure victims file at the time of exposure in an effort to secure some share of the injurer's limited assets. Conversely, $\widetilde{q}=1$ implies that there is no race, i.e., all victims wait to file.

We begin by defining the injurer's expected liability costs (damages plus litigation costs) under the traditional rule that bars suits at the time of exposure:

$$
\bar{L} \equiv N \int_{0}^{1} q\left(D+c_{i}\right) f(q) d q
$$

where $c_{i}$ is the injurer's cost per suit, and $N$ is the total number of exposure victims. We consider two cases. In the first, the injurer's assets, $A,{ }^{13}$ are insufficient to cover $\bar{L}$ (i.e., $A<\bar{L}$ ). In this case, bankruptcy is inevitable, regardless of whether or not a tort for risk is allowed. Below, we consider the case where $A \geq \bar{L}$; that is, the injurer has sufficient assets to cover his expected liability costs provided no victims file at exposure

\footnotetext{
${ }^{13} A$ should be interpreted here as the injurer's assets at the beginning of $\mathrm{t}=1$, i.e., after any expenditure on care. Thus, if $A_{o}$ is the asset level at the beginning of $\mathrm{t}=0$, then $A=A_{o}-x$. See Section 4.B below.
} 
(bankruptcy is not inevitable). In that case, we ask whether allowing exposure suits would trigger a race to file that would not have existed otherwise. In both cases, however, we assume that $A>N\left(c_{v}+c_{i}\right)$. This ensures that litigation costs alone would not bankrupt the injurer even in the most extreme race to file. Specifically, all victims would find suits profitable since $A / N-c_{i}>c_{v}$. This assumes that the injurer must pay his own litigation costs first, and then pays any damages out of his remaining assets (if any).

\section{A. Bankruptcy Inevitable: $A<\bar{L}$.}

To determine the existence and characteristics of a Nash equilibrium filing threshold, we first assume (as noted above) that victims choose to file at the time of exposure if and only if $q>\widetilde{q}$, and then determine the conditions under which this is optimal for each individual victim given that all other victims behave in this way. Thus, given this general strategy by all (other) victims, we must determine the payoffs from filing at exposure, and from waiting, for each individual victim. However, because these payoffs depend upon the magnitude of $\widetilde{q}$, we must consider the following possible ranges:

(1): $\tilde{q}$ is sufficiently low (i.e., the number of victims who file suit at the time of exposure is sufficiently high) that the injurer is driven to bankruptcy in $t=1$. This occurs when $0 \leq \widetilde{q}<q^{\prime}$ (where $q^{\prime}$ is defined below).

(2): $\tilde{q}$ is in an intermediate range such that the injurer still has some assets remaining after paying all litigation and liability costs associated with exposure suits, but those assets are insufficient to cover fully all litigation costs if all remaining illness victims seek damages at time of illness. In this case, some but not all of the illness victims who did not file at the time of exposure file at the time of damages. This occurs when $q^{\prime} \leq \widetilde{q}<\hat{q}$ (where $\hat{q}$ is defined below).

(3): $\widetilde{q}$ is sufficiently high (i.e., the number of victims who file at the time of exposure is sufficiently low) that the injurer's remaining assets are sufficient to cover all litigation costs if all remaining illness victims file suit at the time of illness. This occurs when $\hat{q} \leq \widetilde{q} \leq 1$. 
Within each of these ranges, we derive the optimal strategy for an individual victim by comparing her return if she files at the time of exposure to her expected return if she waits.

(1): $0 \leq \widetilde{q}<q^{\prime}$. To define this range precisely, let $q^{\prime}$ be implicitly defined by

$$
A=N \int_{q^{\prime}}^{1}\left(q D+c_{i}\right) f(q) d q \equiv T C_{1}\left(q^{\prime}\right) .
$$

Thus, $q^{\prime}$ is defined as the probability of illness such that, if all exposure victims with $q \geq q^{\prime}$ file suit at time of exposure, the injurer's assets will be just sufficient to cover both the liability payment, which is equal to $q D,{ }^{14}$ and the litigation costs associated with these suits. Note that $q^{\prime}$ is increasing in the injurer's litigation costs $\left(c_{i}\right)$ and damages $(D)$, and decreasing in the injurer's assets $(A)$.

If $\widetilde{q}<q^{\prime}$, then, after paying his litigation costs, the injurer's remaining assets are insufficient to cover the expected damages of the victims who file at exposure. We assume that in this case each victim receives an equal share, $\beta(\widetilde{q})$, of her expected damages given by

$$
\beta(\widetilde{q})=\frac{A-N \int_{\widetilde{q}}^{1} c_{i} f(q) d q}{N \int_{\widetilde{q}}^{1} q D f(q) d q}<1,
$$

where $\beta(\widetilde{q})$ depends on the number of victims filing suit at exposure. Note that $\partial \beta / \partial \widetilde{q}>0$, implying that a reduction in the number of victims who file in $\mathrm{t}=1$ increases the share of assets that each victim receives. 
If $0 \leq \widetilde{q}<q^{\prime}$, then the injurer's assets are fully exhausted in $\mathrm{t}=1$. Consequently, victims who wait to file until $\mathrm{t}=2$ receive nothing. Thus, if $\widetilde{q}$ lies within this range, a rational victim's best response is to file at exposure if and only if

$$
\beta(\widetilde{q}) q D-c_{v}>0,
$$

i.e., if and only if

$$
q>\frac{c_{v}}{\beta(\widetilde{q}) D} \equiv J(\widetilde{q})
$$

where $J^{\prime}(\widetilde{q})<0$ and $J\left(q^{\prime}\right)=c_{v} / D$. Note that an increase in $A$ will increase $\beta(\widetilde{q})$ and hence shift $J(\widetilde{q})$ downward.

For expositional purposes, we consider range 3 next.

(3): $\hat{q} \leq \widetilde{q} \leq 1$. To define this range, note first that

$$
S_{2}(\widetilde{q}) \equiv N \int_{0}^{\widetilde{q}} q f(q) d q
$$

is the expected number of suits in $\mathrm{t}=2$ if all victims who did not file an exposure suit in $t=1$ file if and when they contract the illness. Also, note that

$$
R(\widetilde{q}) \equiv A-T C_{1}(\widetilde{q})-c_{i} S_{2}(\widetilde{q})
$$

represents the assets the injurer has available to pay damages to victims in period two after paying his own litigation costs (where $T C_{l}$ is defined above in (2)). We can now define $\hat{q}$ as the solution to

$$
R(\hat{q})=c_{v} S_{2}(\hat{q})
$$

Thus, $\hat{q}$ is the probability such that, if all exposure victims with $q \geq \hat{q}$ file at the time of exposure and all remaining illness victims file at the time of illness, the injurer's

\footnotetext{
${ }^{14}$ See Robinson (1985) and Rose-Ackerman (1989).
} 
remaining assets, after paying the total costs associated with these exposure suits plus the litigation costs associated with the illness suits, are just sufficient to cover all of the victims' litigation costs.

It is easy to show that $\hat{q}>q^{\prime} .{ }^{15}$ Thus, if $\widetilde{q}>\hat{q}$, the injurer will not be driven into bankruptcy by the exposure suits and all victims who file at exposure will receive their full expected damages $(q D)$ rather than a pro-rated share. Furthermore, the share of remaining assets that each illness victim would receive if all remaining illness victims file suit in $\mathrm{t}=2$, given by $r(\widetilde{q}) \equiv R(\widetilde{q}) / S_{2}(\widetilde{q})$, would be sufficient to cover each illness victim's litigation costs. Hence, conditional on not having filed suit in $t=1$, all remaining illness victims would choose to file suit in $\mathrm{t}=2$ since the net return from filing $\left(r(\widetilde{q})-c_{v}\right)$ is positive.

The preceding implies that, if $\hat{q} \leq \tilde{q} \leq 1$, a victim's best response is to choose to file at exposure rather than waiting to file at the time of illness if and only if

$$
q D-c_{v}>q\left[r(\widetilde{q})-c_{v}\right]
$$

i.e., if and only if

$$
q>\frac{c_{v}}{c_{v}+D-r(\widetilde{q})} \equiv H(\widetilde{q})
$$

where $H^{\prime}(\widetilde{q})>0$ and $H(\hat{q})=c_{v} / D$. In addition, $H(1)<1$ given that $A<\bar{L}$.

Finally, we consider the middle range:

(2): $q^{\prime} \leq \widetilde{q}<\hat{q}$. If $\widetilde{q}$ lies within this range, then even though the injurer would not be bankrupt at the end of $\mathrm{t}=1$, he would not have sufficient remaining assets to make it

\footnotetext{
${ }^{15}$ To see this, note that from (2), $A-T C_{l}(q)=0$, while from (6) and (7), $A-T C_{1}(\hat{q})=S_{2}(\hat{q})\left(c_{i}+c_{v}\right)>0$. Since $\partial T C_{1} / \partial \widetilde{q}<0$, it follows immediately that $\hat{q}>q^{\prime}$.
} 
worthwhile for all remaining illness victims to file at $\mathrm{t}=2$. However, it would still be worthwhile for some fraction of those remaining victims to file. ${ }^{16}$ Conditional on not filing in $t=1$, an illness victim would want to file suit in $t=2$ if and only if her recovery from the suit exceeds her litigation costs. A strictly positive net return from filing suit would induce additional victims to file. In other words, in $\mathrm{t}=2$ illness victims would "compete" for the injurer's remaining assets. This competition would drive down the recovery per suit to a point where victims are indifferent between filing and not filing. Additional victims would continue to sue until the recovery from a suit just equals the associated litigation costs. Thus, for $\widetilde{q}$ in this range, the net return from filing a suit (recovery less litigation costs) is driven to zero. As a result, within this range, the optimal response of the victim is to file at exposure rather than illness if and only if

$$
q D-c_{v}>0,
$$

i.e., if and only if

$$
q>c_{\sqrt{ }} / D .
$$

The conditions in (4), (8) and (9) give the optimal response of an individual victim to the strategy of the other victims over the possible ranges of $\widetilde{q}$. We can combine these into a single condition which states that the optimal response of a victim with an exposure level $q$ is to file at the time of exposure if and only if $q>G(\widetilde{q})$, where

$$
\begin{array}{rll}
J(\widetilde{q}) & \text { if } & 0 \leq \widetilde{q}<q^{\prime} \\
G(\widetilde{q}) \equiv c_{v} / D & \text { if } & q^{\prime} \leq \widetilde{q}<\hat{q} \\
H(\widetilde{q}) & \text { if } & \hat{q} \leq \widetilde{q} \leq 1
\end{array}
$$

\footnotetext{
${ }^{16}$ It is conceptually possible that the remaining assets would be so low that it would not be worthwhile for even a single remaining victim to file suit at $t=2$, thereby leaving the injurer with some assets at the end of $\mathrm{t}=2$. However, we can ignore this case without affecting our results qualitatively.
} 
Given the premise that victims file suit at exposure if and only if $q>\widetilde{q}$, Proposition 1 follows immediately:

Proposition 1: $\widetilde{q}$ is a Nash equilibrium threshold probability if and only if $\widetilde{q}=G(\widetilde{q})$.

Figure 1 shows the possible types of Nash equilibria, which occur where the 45degree line intersects $G(\widetilde{q})$. In Figure 1a, the 45-degree line intersects $G(\widetilde{q})$ in the range $0 \leq \widetilde{q}<q^{\prime}$ (where $G(\tilde{q})=J(\widetilde{q})$ ), implying the existence of a Nash equilibrium in which the injurer is driven to bankruptcy by exposure suits. As $A$ increases, the horizontal segment between $q^{\prime}$ and $\hat{q}$ shifts to the left, with corresponding shifts in $J$ and $H$. As this shift occurs, the new intersection point first moves to the horizontal segment (Figure 1b), generating an equilibrium in which the injurer is not bankrupted by exposure suits, but illness victims compete away the injurer's remaining assets, leaving victims who file at illness with no net gain from their suits. Further increases in $A$ eventually yield an intersection point to the right of $\hat{q}$ (Figure 1c), generating an equilibrium in which bankruptcy again does not occur until $t=2$, but illness victims receive compensation that more than covers their litigation costs. ${ }^{17}$

Regardless of which type of equilibrium occurs, however, we have the following:

Proposition 2: An equilibrium $\widetilde{q}$ always exists, and in equilibrium $c_{v} / D \leq \widetilde{q}<1$.

Proof: Note first that $G(0) \equiv J(0)<1$ (given $A>N\left(c_{i}+c_{v}\right)$ ) and $G(1) \equiv H(1)<1$ (given $A<\bar{L})$. Also, $J\left(q^{\prime}\right)=H(\hat{q})=c_{v} / D \geq 0$. Finally, $J$ is monotonically decreasing and $H$ is monotonically increasing. Thus, $G$ is a continuous function that maps from $[0,1] \rightarrow[0,1]$. By Brouwer's Fixed Point Theorem, there exists a $\widetilde{q}$ such that $G(\tilde{q})=\tilde{q}$. Further, since $c_{v} / D \leq G(\widetilde{q})<1$ for all $\widetilde{q}$, at the fixed point $c_{v} / D \leq \widetilde{q}<1$. Q.E.D.

\footnotetext{
${ }^{17}$ Note that, because $H(\widetilde{q})$ is not necessarily convex, we cannot rule out the possibility of multiple equilibria in this range.
} 
The implication of Proposition 2 is that, with inevitable bankruptcy triggered by liability, allowing a tort for risk will induce some victims to "race to file" in order to receive as much compensation as possible. However, as long as litigation costs are positive, the race is not complete in the sense that not all victims file at exposure (i.e., $\widetilde{q}$ is bounded below by $c_{v} / D$ ). The existence of positive litigation costs for victims prevents a total race. ${ }^{18}$ As a result, even though the injurer always faces eventual bankruptcy if an accident occurs (by assumption), allowing a tort for risk will not necessarily drive the injurer into immediate bankruptcy by inducing all (or even most) victims to file at exposure.

Allowing a tort for risk, however, will change the distribution of the injurer's limited assets in favor of high $q$ victims. Note that with no tort for risk, all victims who ultimately suffer damages receive the same compensation amount (regardless of how likely it was in an ex ante sense that they would contract the disease), while those who do not contract the disease receive nothing. Under the tort for risk with endogenous bankruptcy, however, high exposure victims, i.e., victims with high values of $q$ resulting from prolonged exposure or spatial proximity to the hazardous substances, effectively have the first claim on the injurer's limited assets. ${ }^{19}$ It is only after the expected damages for these victims (those most likely to ultimately contract the disease) are covered that victims who were less likely to contract the illness (because of low exposure), but who ultimately do, receive any compensation. Thus, allowing a tort for risk effectively treats

\footnotetext{
${ }^{18}$ Recall, however, that in the absence of a tort for risk, even with positive litigation costs all illness victims would file at the time of illness, given our assumption that $D>c_{v}$.

${ }^{19}$ In addition, when recovery for emotional distress is not allowed, a tort for risk serves to at least partially compensate high probability victims for their presumably higher emotional distress.
} 
exposure as the primary tortious act, providing compensation for victims with high exposure first, and then allowing any remaining assets to be used for compensation of illness victims who did not file at $t=1$. In other words, a tort for risk effectively creates two classes of victims: a primary class comprised of high exposure victims who have first claim to the injurer's limited assets, and a secondary class comprised of low exposure victims who ultimately contract the disease and who can then make a claim on any remaining assets only after the exposure damages for the primary class have been covered. In contrast, with suits only allowed at the time of illness, there is a single class of victims (all those who contract the disease) who are given equal priority regardless of the intensity of exposure.

\section{B. Bankruptcy Not Inevitable: $A \geq \bar{L}$.}

Having characterized the Nash equilibria for the case where bankruptcy is inevitable, we now turn to the question of whether allowing a tort for risk could trigger bankruptcy in a situation where the injurer would not go bankrupt if the tort for risk were not allowed.

In the absence of a tort for risk, the injurer's expected liability-related costs continue to be given by $\bar{L}$. Thus, as long as the injurer's assets are at least equal to $\bar{L}$, he will be able to cover his expected liability if a tort for risk is barred. However, if a tort for risk is allowed, then for an arbitrary value of $\widetilde{q}$, the injurer's total expected liability could be higher. Compare, for example, total expected liability if a tort for risk is not allowed $(\bar{L})$ to the total first-period costs when a tort for risk is allowed but the injurer is not bankrupt in this period (defined above by $T C_{1}(\widetilde{q})$ ). Depending on the value of $\widetilde{q}$, it is possible to have an asset level $A$ such that 


$$
T C_{1}(\widetilde{q}) \equiv N \int_{\widetilde{q}}^{1}\left(q D+c_{i}\right) f(q) d q>A>N \int_{0}^{1} q\left(D+c_{i}\right) f(q) d q \equiv \bar{L} .
$$

Because the injurer incurs the litigation costs associated with exposure suits with certainty when a tort for risk is allowed (i.e., $c_{i}$ is not multiplied by $q$ in $T C_{1}(\widetilde{q})$ ), the total costs associated with a tort for risk could actually exceed the costs the injurer would incur if such suits were barred, and this additional cost (due to potentially higher litigation costs) could be sufficiently large to induce bankruptcy. The question, then, is whether this potential outcome (for an arbitrary $\tilde{q}$ ) emerges as an equilibrium outcome.

We begin by stating the following result.

Proposition 3: If $A \geq \bar{L}$, then $\widetilde{q}=1$ is a Nash equilibrium, i.e., even though a tort for risk is allowed, in one possible equilibrium no victims choose to sue at the time of exposure.

To see this, we reconsider the analysis from the previous section on inevitable bankruptcy and note that the only place in which the condition $A<\bar{L}$ was used in that analysis was to show that $H(1)<1$. It follows that $H(1) \geq 1$ if and only if $A \geq \bar{L}$. Now, in order for $\widetilde{q}=1$ to be an equilibrium, it must be the case that $q \leq H(1)$ for all $q$, which clearly holds if $H(1) \geq 1$. Thus, all victims prefer to file at illness. Intuitively, with $\widetilde{q}=1$, each victim who chooses to wait has an expected net payment of $q\left(D-c_{v}\right)$ (since there is no bankruptcy). In contrast, should a victim choose to sue at exposure, she could receive at most a net payment of $q D-c_{v}$ (and possibly less, if exposure suits trigger bankruptcy). Thus, given that all other victims choose to wait, no individual victim can increase her expected payment by filing at exposure. As a result, $\widetilde{q}=1$ (all victims wait) is a Nash equilibrium. 
Proposition 3 implies that allowing a tort for risk will not necessarily induce a race to file in the case where bankruptcy is not inevitable. If the injurer has sufficient assets to cover all suits at illness, then even though victims have the option to sue for exposure, in this equilibrium they would choose not to do so. The question is whether there exist other equilibria under which a race to file and bankruptcy would result.

It is certainly possible that the equilibrium under which all victims wait is a unique equilibrium. This can be seen by modifying the figures from the case of inevitable bankruptcy to reflect $H(1) \geq 1$ rather than $H(1)<1$. The case where $\widetilde{q}=1$ is a unique equilibrium is depicted in Figure 2. This outcome, however, is not guaranteed. In general, we cannot rule out the possibility of other equilibria under which a race to file occurs even though the injurer would have sufficient assets to cover all suits at illness. Figure 3 depicts such a case.

To compare the possible equilibria, we first note the following:

Proposition 4: In any equilibrium with $\widetilde{q}<1$, the injurer is bankrupted by liability. To see this, note that, of the values of $\widetilde{q}$ for which $H(\widetilde{q}) \geq 1$ (the points on the line segment connecting D and C in Figure 3), only $\widetilde{q}=1$ is an equilibrium. Thus, if $\widetilde{q}<1$, then $H(\widetilde{q})<1$, and since $H(\widetilde{q})<1$ implies that the injurer's total expected costs exceed $A$, any equilibrium with $\widetilde{q}<1$ must imply bankruptcy. In other words, it is not possible to have an equilibrium race-to-file that does not end in bankruptcy. Thus, in Figure 3, while the injurer would not be bankrupted by liability in equilibrium C (where $\widetilde{q}=1$ ), he would be bankrupted at either of the other two equilibria (A or B). (In both cases depicted, the injurer is not bankrupted by exposure suits but has insufficient remaining assets to cover the potential liability he faces from illness suits.) Thus, when there are 
multiple equilibria, allowing a tort for risk can trigger bankruptcy when it would not otherwise have occurred. $^{20}$

Why in equilibrium might there be a race to file which triggers bankruptcy if bankruptcy is not inevitable? The intuitive explanation is as follows. As we argued above, if one victim expects all others to file at illness, then that victim will be better off waiting to file as well rather than filing at exposure. However, if a victim expects enough other victims to file at exposure to trigger bankruptcy, i.e., if she expects a value of $\widetilde{q}$ at which $H(\widetilde{q})<1$, then provided her value of $q$ exceeds $\widetilde{q}$, she will be better off filing at exposure as well. Thus, equilibria with $\widetilde{q}<1$ (and hence injurer bankruptcy) can emerge as Nash equilibria, even though bankruptcy is not inevitable.

Note, however, that the no-bankruptcy equilibrium Pareto dominates in the sense that all victims are better off at an equilibrium with $\tilde{q}=1$ than they would be at any equilibrium with $\widetilde{q}<1$. This is because if $\widetilde{q}=1$ equilibrium, each victim has an expected payoff of $q\left(D-c_{v}\right)$, whereas if $\widetilde{q}<1$, each victim has a lower expected payoff. Those who file at exposure have an expected payoff of at most $q D-c_{v}$, those who file at illness have an expected payoff less than $q\left(D-c_{\nu}\right)$, and those who never file have an expected payoff of zero. ${ }^{21}$ Thus, victims should always prefer the $\widetilde{q}=1$ equilibrium. 4 .

\section{Litigation Costs and Injurer Care}

To this point, we have characterized the impact of allowing a tort for risk on the filing equilibrium. In this section, we turn to the question of whether allowing a tort for

\footnotetext{
${ }^{20}$ It is easy to show that as $A$ increases, eventually the only equilibrium is the one at $\widetilde{q}=1$ (the case illustrated in Figure 2), in which case bankruptcy cannot occur.

${ }^{21}$ In the $\widetilde{q}=1$ equilibrium, it is profitable for all victims to file suit at illness, given $D>c_{v}$.
} 
risk is more efficient in the sense of yielding lower total social costs. This depends on the resulting litigation and damage costs, which we consider in turn.

\section{A. Impact on Litigation Costs}

As noted previously, the conventional wisdom is that allowing a tort for risk would increase the number of suits and hence increase overall litigation costs. We have shown above that the tort for risk could induce a race to file, even in a context where bankruptcy is not inevitable. However, we show here that such a race does not necessarily imply higher litigation costs (relative to an outcome where exposure suits are not allowed). Our main result is the following.

Proposition 5: In equilibrium the total number of suits may be higher or lower when a tort for risk is allowed.

To show this, we first note that not allowing a tort for risk is equivalent to setting $\widetilde{q}=1$.

In this case, (5) implies that the expected number of suits is simply

$S_{2}(1)=N \int_{0}^{1} q f(q) d q \cdot{ }^{22}$ To prove the proposition, it is sufficient to find one type of

equilibrium under the tort for risk for which the number of suits is not necessarily greater.

Consider an equilibrium in which no suits occur in $t=2$ (see Figure 1a). In this

equilibrium, the total number of suits is simply $S_{1}(\widetilde{q})=N \int_{\widetilde{q}}^{1} f(q) d q$. Clearly, $S_{1}(\widetilde{q})$ can

be less than $S_{2}(1)$, depending on the value of the equilibrium $\widetilde{q}$. For example, if $q$ is uniformly distributed on $[0,1]$, then $S_{1}(\tilde{q})$ is less than $S_{2}(1)$ as long as $\widetilde{q}>1 / 2$ in equilibrium.

${ }^{22}$ The assumption that $A>N\left(c_{i}+c_{v}\right)$ is sufficient to ensure that all these suits are profitable. 
Proposition 5 implies that, in contrast to the conventional wisdom, allowing a tort for risk does not necessarily increase the number of suits and hence overall litigation costs. The intuition is as follows. Even though under a tort for risk exposure suits by those filing at $\mathrm{t}=1$ occur with certainty (while these same victims would file at $\mathrm{t}=2$ with probability $q$ if the tort for risk were barred), the population of victims who sue at some point (either $t=1$ or $t=2$ ) is potentially smaller when a tort for risk is allowed. For example, under the equilibrium in Figure 1a, victims with $q<\widetilde{q}$ never file when the tort for risk is allowed, but they would file with probability $q$ if such suits were not allowed.

\section{B. Incentives for Care}

The above results suggest that alternative values of $\widetilde{q}$ cannot be ranked on the basis of litigation costs. We turn next to the question of how they compare in terms of incentives for injurer care.

It should be clear from the discussion above that in the case where $A<\bar{L}$, if an accident occurs, the injurer expects to pay out his entire assets in the form of compensation and/or litigation costs in any of the three types of possible equilibria,. Thus, the total cost of an accident to the injurer is independent of $\widetilde{q}$. However, as noted by Beard (1990), the injurer's asset level at the time an accident occurs depends on his prior expenditure on care, i.e., $A=A_{o}-x$, where $A_{o}$ is the injurer's initial asset level. Thus, bankruptcy is inevitable if the injurer chooses a level of care greater than $A_{o}-\bar{L}$. In addition, even when bankruptcy is not inevitable, the injurer may still choose a level of care that creates the possibility of an equilibrium in which there is a race to file that results in bankruptcy. Both of these possibilities must be considered when examining the 
incentive effects of allowing a tort for risk. Our main result regarding the impact of allowing a tort for risk on the injurer's choice of care is given in Proposition 6:

Proposition 6: (i) If the optimal choice of care when a tort for risk is not allowed leads to inevitable bankruptcy if an accident occurs, i.e., if the optimal x exceeds $A_{o}-\bar{L}$, then allowing a tort for risk does not affect the injurer's choice of care. (ii) If the optimal choice of care when a tort for risk is not allowed does not lead to inevitable bankruptcy, i.e., if the optimal $x$ is less than $A_{o}-\bar{L}$, then allowing a tort for risk will either leave the injurer's choice of care unchanged or increase it, depending upon the type of equilibrium that is expected to emerge. If a $\widetilde{q}=1$ equilibrium is expected to emerge when bankruptcy is not inevitable, then allowing a tort for risk will not affect the injurer's choice of care.

Intuitively, allowing a tort for risk will affect the injurer's care choice only if it affects the total amount he expects to pay out in exposure-related costs. ${ }^{23}$ This occurs only when the injurer would not be bankrupt in the absence of a tort for risk but expects to be bankrupted if a tort for risk is allowed. In this case, however, allowing a tort for risk increases the injurer's total expected pay out, and hence increases his level of care. The effect of a tort for risk on the injurer's choice of care is derived more explicitly in the Appendix.

Proposition 6 implies that the effect of a tort for risk on care choices stems from the possibility that allowing a tort for risk will lead to a race-to-file that ends in bankruptcy even when bankruptcy is not inevitable. However, as noted above, whenever such an equilibrium exists, there is also a no-bankruptcy equilibrium under which a race to file does not occur, and this equilibrium Pareto dominates in the sense that all victims are at least as well off as they are under a race-to-file equilibrium. If Pareto dominance makes this equilibrium more likely to occur, then Proposition 6 suggests that, in contrast

\footnotetext{
${ }^{23}$ Note that Proposition 6 does not imply that the potential for bankruptcy has no effect on the choice of care. As shown by Beard (1990), the potential for bankruptcy can lead to either under- or over-deterrence.
} 
to the result with exogenous bankruptcy, allowing a tort for risk would not be expected to lead to greater deterrence. Thus, neither the increased litigation costs nor the greater deterrence that arose under a tort for risk with exogenous bankruptcy necessarily arise when bankruptcy is endogenous.

\section{Conclusion}

Conventional tort law does not permit victims of exposure to a toxic substance to seek compensation until they actually develop symptoms of illness. However, this rule often has the practical effect of barring recovery because, by the time the illness arises, the injurer may be judgment-proof, or victims may have difficulty in proving causation. A possible solution is to allow victims to sue for expected damages at the time of exposure - that is, to create a tort for risk. Critics of this idea, however, warn that it would create a flood of litigation that could bankrupt the injurer. This paper has evaluated the impact of a tort for risk on the filing decisions of victims, as well as the resulting effect on litigation costs and injurer care.

To examine the impact of a tort for risk on victims' filing decisions, we considered two scenarios: one in which the injurer's assets were less than his expected damages plus litigation costs in the absence of a tort for risk, and one in which his assets exceeded those costs. In the first case, where bankruptcy is inevitable, the effect of a tort for risk is to induce some, but not all, victims to file suit at exposure. In equilibrium, victims with the higher probabilities of developing the illness choose to file early while those with lower probabilities either wait or do not file at all. Thus, a tort for risk

Proposition 6 simply states that, regardless of the optimal level of $x$, allowing a tort for risk can never lead to less deterrence than would have existed under the conventional rule where only illness suits are allowed. 
effectively creates a priority rule that gives high exposure victims first claim on the injurer's limited assets. In contrast, the traditional tort rule gives priority to victims who actually develop the illness, regardless of their ex ante risk.

In the case where the injurer is not expected to be bankrupted by illness suits, we showed that there always exists an equilibirum in which all victims wait to file at illness. Nevertheless, there also exist other equilibria in which a "race to file" occurs and results in bankruptcy. Not surprisingly, the equilibrium in which all victims wait to file is Pareto dominant in that all victims expect to receive a higher return.

We also evaluated the impact of a tort for risk on the expected number of suits and injurer care. We first showed that, although a tort for risk induces some victims to file at the time of exposure, it does not necessarily increase the overall number of suits. The reason is that the initial race to file may foreclose additional future suits by bankrupting the injurer or leaving him with insufficient assets to make such suits profitable. As for injurer care, we showed that a tort for risk will affect the injurer's optimal choice of care only if it affects the total amount that he expects to pay in liabilityrelated costs. In particular, if the injurer would not have been bankrupted under the traditional rule but is bankrupted under a tort for risk, then he will take greater care under the latter rule.

Our results provide some insight into whether the tendency for the law to deny tort-for-risk claims can be supported by economic principles. Clearly, in the case where bankruptcy is not inevitable, denying such claims, which in our model amounts to ensuring an equilibrium where there is no race to file, is socially preferred in that all victims are better off, litigation costs are lower, and care is at least as high as it would 
have been if a tort-for-risk were allowed. However, when bankruptcy is inevitable, our results suggest that barring such claims will not necessarily be socially preferred. In this case, some victims will be better off with a tort-for-risk than without one (allowing a tortfor-risk changes the priority rule), and litigation costs can be higher or lower when a tortfor-risk is allowed. Thus, while the law "got it right" in cases where bankruptcy is not an inevitable, this conclusion may not hold when the liability costs associated with exposure are sufficiently large to bankrupt the firm. 


\section{Appendix}

To show the effect of allowing a tort for risk on injurer care, we must first consider the injurer's optimal care choice when there is no tort for risk. In this case, the injurer's expected liability costs (damages plus litigation costs) are $\bar{L}$ as defined by (1). Thus, the injurer will be bankrupted if he chooses a level of $x$ greater than $A_{o}-\bar{L}$, in which case he will have to pay out all of his remaining assets, $A_{o^{-}} x$; and he will not be bankrupted if he chooses $x$ less than $A_{o}-\bar{L}$, in which case he will have to pay $\bar{L}$. The injurer's problem can therefore be written:

$$
\operatorname{minimize} \begin{aligned}
& \min _{x \leq A_{o}-\bar{L}} x+p(x) \bar{L} \\
& \min _{x>A_{o}-\bar{L}} x+p(x)\left(A_{o}-x\right)
\end{aligned}
$$

Consider first the top line, where the injurer is not bankrupted. Assuming the constraint is not binding, the injurer chooses care of $\hat{x}$ to solve ${ }^{24}$

$$
1+p^{\prime}(x) \bar{L}=0
$$

Conversely, if the injurer chooses a level of care that results in bankruptcy, his optimal care choice, $\tilde{x}\left(A_{o}\right)$, solves

$$
1+p^{\prime}(x)\left(A_{o}-x\right)-p(x)=0 .
$$

Clearly, $\widetilde{x}(0)=0$. It is also easy to show that both $\widetilde{x}\left(A_{o}\right)$ and the minimized value of costs are increasing in $A_{o}$. In addition, one can show that $\partial \tilde{x} / \partial A_{o}<1$ (Beard, 1990). Thus, $A_{o}-\widetilde{x}\left(A_{o}\right)$ is increasing in $A_{o}$. This implies that the inequality $\widetilde{x}\left(A_{o}\right)>A_{o}-\bar{L}$ must be satisfied for low values of $A_{o}$, though it will eventually reverse as $A_{o}$ rises.

\footnotetext{
${ }^{24}$ Note that this level of care is less than the socially efficient level since, even though the injurer pays the total expected damages and his own litigation costs, he ignores the victim's litigation costs.
} 
The critical asset level at which the injurer is indifferent between bankruptcy and no bankruptcy, denoted $A_{o}{ }^{\prime}$, solves the equation

$$
\hat{x}+p(\hat{x}) \bar{L}=\widetilde{x}\left(A_{o}^{\prime}\right)+p\left(\widetilde{x}\left(A_{o}^{\prime}\right)\right)\left(A_{o}^{\prime}-\widetilde{x}\left(A_{o}^{\prime}\right)\right) .
$$

(See Figure 4.) It follows that injurers with $A_{o}<A_{o}{ }^{\prime}$ minimize costs by choosing $\widetilde{x}\left(A_{o}\right)$ and becoming bankrupt, ${ }^{25}$ whereas injurers with $A_{o} \geq A_{o}{ }^{\prime}$ choose $\hat{x}$ and do not become bankrupt. The graph shows that at the indifference point, $\widetilde{x}\left(A_{o}^{\prime}\right)>\hat{x}$. To prove that this is true, assume the contrary. That is, assume $\widetilde{x}\left(A_{o}^{\prime}\right) \leq \hat{x}$. Thus, the cost curves in Figure 4 must intersect at a point $x^{\prime}$ such that $\tilde{x}\left(A_{o}^{\prime}\right) \geq x^{\prime} \geq \hat{x}$ where

$$
x^{\prime}+p\left(x^{\prime}\right) \bar{L}=x^{\prime}+p\left(x^{\prime}\right)\left(A_{o}^{\prime}-x^{\prime}\right)
$$

It follows that $\bar{L}=A_{o}^{\prime}-x^{\prime}$, but given that $x^{\prime} \leq \tilde{x}\left(A_{o}^{\prime}\right)$, it must be true that $\bar{L} \leq A_{o}^{\prime}-\widetilde{x}\left(A_{o}^{\prime}\right)$, which contradicts the injurer's bankruptcy at $A_{o}{ }^{\prime}$.

Given the above results, we now consider how the introduction of a tort for risk affects injurers' care choices. Consider first cases where introduction of a tort for risk leads to an equilibrium with $\tilde{q}<1$. Recall that, according to Proposition 4 , any such equilibrium results in injurer bankruptcy. Thus, injurers whose choice resulted in bankruptcy without a tort for risk (i.e., those with $A_{o}<A_{o}{ }^{\prime}$, for whom bankruptcy was inevitable) will not change their care choice if a tort for risk is allowed because the asset

\footnotetext{
${ }^{25}$ To see that at $A_{o}{ }^{\prime}$ the injurer is in fact bankrupt when he chooses $\widetilde{x}\left(A_{o}^{\prime}\right)$, note that $\widetilde{x}\left(A_{o}^{\prime}\right)+p\left(\widetilde{x}\left(A_{o}^{\prime}\right)\right) \bar{L}>\hat{x}+p(\hat{x}) \bar{L}$ given the definition of $\hat{x}$. It therefore follows from (A4) that $\widetilde{x}\left(A_{o}^{\prime}\right)+p\left(\widetilde{x}\left(A_{o}^{\prime}\right)\right) \bar{L}>\widetilde{x}\left(A_{o}^{\prime}\right)+p\left(\widetilde{x}\left(A_{o}^{\prime}\right)\right)\left(A_{o}^{\prime}-\widetilde{x}\left(A_{o}^{\prime}\right)\right)$,
} 
constraint was already binding. However, injurers whose care choice did not lead to bankruptcy with no tort for risk but are now bankrupted by the higher liability costs under a tort for risk (i.e., those with $A_{o}>A_{o}$ ) will switch from $\hat{x}$ to $\widetilde{x}\left(A_{o}\right)$; and since we have seen that $\widetilde{x}\left(A_{o}^{\prime}\right)>\hat{x}$, it must be true that $\widetilde{x}\left(A_{o}\right)>\hat{x}$ for $A_{o}>A_{o}{ }^{\prime}$ given $\partial \widetilde{x} / \partial A_{o}>0$. Finally, if the equilibrium under a tort for risk turns out to be one with $\widetilde{q}=1$, then introduction of the tort for risk does not increase the injurer's costs and hence has no effect on care.

which implies that $\bar{L}>A_{o}^{\prime}-\widetilde{x}\left(A_{o}^{\prime}\right)$. 


\section{References}

Bathgate, J. (2001) "The Influence of a Tort for Risk on the Incentive to File Suit in a Costly Legal System," Ph.D. dissertation, Dept. of Economics, Univ. of Connecticut.

Beard, T. (1990) "Bankruptcy and Care Choice," Rand Journal of Economics 21: 626634.

Chapin, Kristen. (1993) "Toxic Torts, Public Health Data, and the Evolving Common Law: Compensation for Increased Risk of Injury," Journal of Energy, Natural Resources and Environmental Law, 13, 129-157.

Dworkin, Terry Morehead. (1984) "Fear of Disease and Delayed Manifestation Injuries: A Solution or a Pandora's Box?" Fordham Law Review, 53, 527-577.

Fischer, Michael J. (1996) "Union Carbide's Bhopal Incident: A Retrospective," Journal of Risk and Uncertainty, 12(2-3), 257-269.

Hamrick, Matthew D. (1998) "Comment: Theories of Injury and Recovery for PostExposure, Pre-Symptom Plaintiffs: The Supreme Court Takes a Critical Look," Cumberland Law Review, 29, 461-488.

Keeton, W. Page, Dan Dobbs, Robert Keeton, and David Owen (1984) Prosser and Keeton on Torts, $5^{\text {th }}$ Ed., St. Paul, Minn.: West Publishing Co.

Landes, William and Richard Posner (1985) "A Positive Economic Theory of Products Liability,” Journal of Legal Studies, 14. 535-567.

Landes, William M. and Posner, Richard A. (1984) "Tort Law as a Regulatory Regime for Catastrophic Personal Injuries," Journal of Legal Studies, 13, 417-434.

Larson, Bruce (1996) "Environmental Policy Based on Strict Liability: Implications of Uncertainty and Bankruptcy," Land Economics 72: 33-42.

Love, Tamsen Douglass. (1996) "SPECIAL PROJECT: Environmental Reform in an Era of Political Discontent: Deterring Irresponsible Use and Disposal of Toxic Substances: The Case for Legislative Recognition of Increased Risk for Causes of Action," Vanderbilt Law Review, 49, 789-823.

McDonnell, Deirdre A. (1997) “Comment: Increased Risk of Disease Damages: Proportional Recovery as an Alternative to the All or Nothing System Exemplified by Asbestos Cases," Bost College Environmental Affairs Law Review, 24, 623-649.

Miceli and Segerson "Should Victims of Exposure to a Toxic Substance Have an Independent Claim for Medical Monitoring?" Research in Law and Economics (forthcoming). 
Miceli and Segerson (2000) "Should There be a Tort for Risk?" Working Paper, Department of Economics, Univ. of Connecticut.

Miller, Kenneth W. (1998) "Note: Toxic Torts and Emotional Distress: The Case for an Independent Cause of Action for Fear of Future Harm," Arizona Law Review, 40, 681707.

Note (1998) "Latent Harms and Risk-Based Damages," Harvard Law Review, 111, 15051522 .

Note (1983) "The Manville Bankruptcy: Treating Mass Tort Claims in Chapter 11 Proceedings," Harvard Law Review, 96, 1121- .

Ringleb, Al H. and Wiggins, Steven N. (1990) "Liability and Large-scale, Long-term Hazards," Journal of Political Economy, 98(3), 574-595.

Robinson, Glen O. (1985) "Probabilistic Causation and Compensation for Tortious Risk," Journal of Legal Studies, 14, 779-798.

Rose-Ackerman, Susan (1989) "Dikes, Dams, and Vicious Hogs: Entitlement and Efficiency in Tort Law," Journal of Legal Studies 18: 25-50.

Rosen, Adam P. (1992) "Emotional Distress Damages in Toxic Tort Litigation: The Move Toward Foreseeability," Villanova Environmental Law Journal, 3, No. 1.

Rosenberg, David. (1984) "The Causal Connection in Mass Exposure Cases: A 'Public Law' Vision of the Tort System," Harvard Law Review, 97, No. 4, 852-929.

Schuck, Peter H. (1992) "The Worst Should Go First: Deferral Registries in Asbestos Litigation," Harvard Journal of Law and Public Policy, 15, 541-59.

Shavell, Steven (1986) "The Judgment Proof Problem," International Review of Law and Economics, 6, 45-58.

Shavell, Steven (1985) "Uncertainty Over Causation and the Determination of Civil Liability," Journal of Law and Economics, 28, 587-609.

Valk, Martin (1995) "Emotional Distress: How I Learned to Stop Fearing Toxic Torts and to Sue for the Fear," Journal of Products and Toxics Liability, 17, 67-79. 


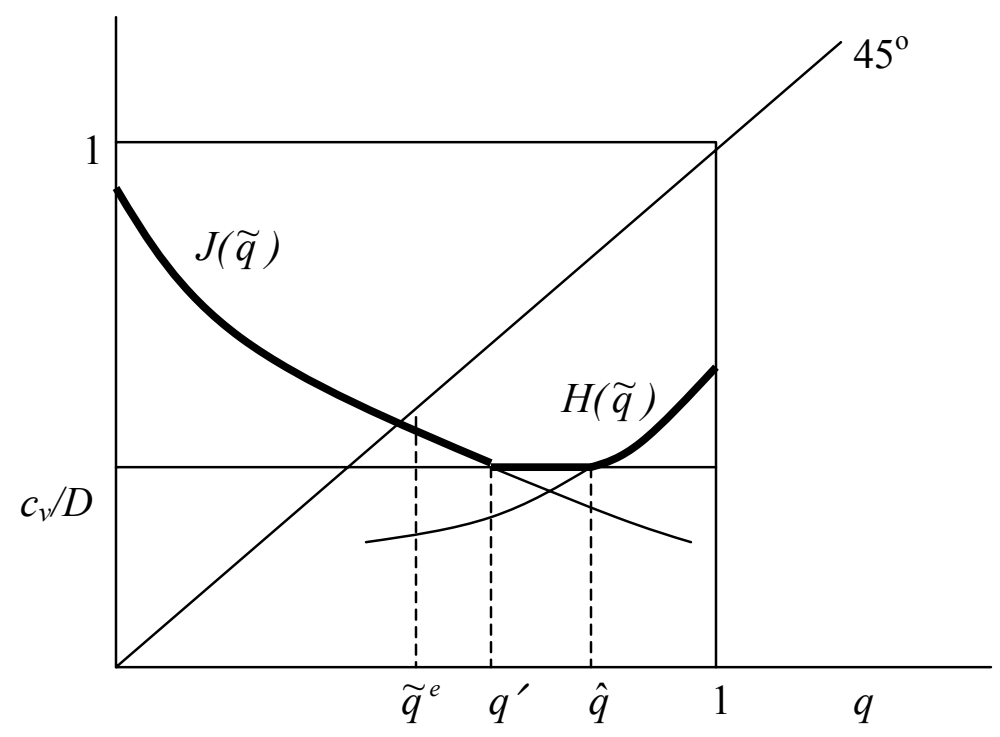

a. Bankruptcy in $\mathrm{t}=1$.

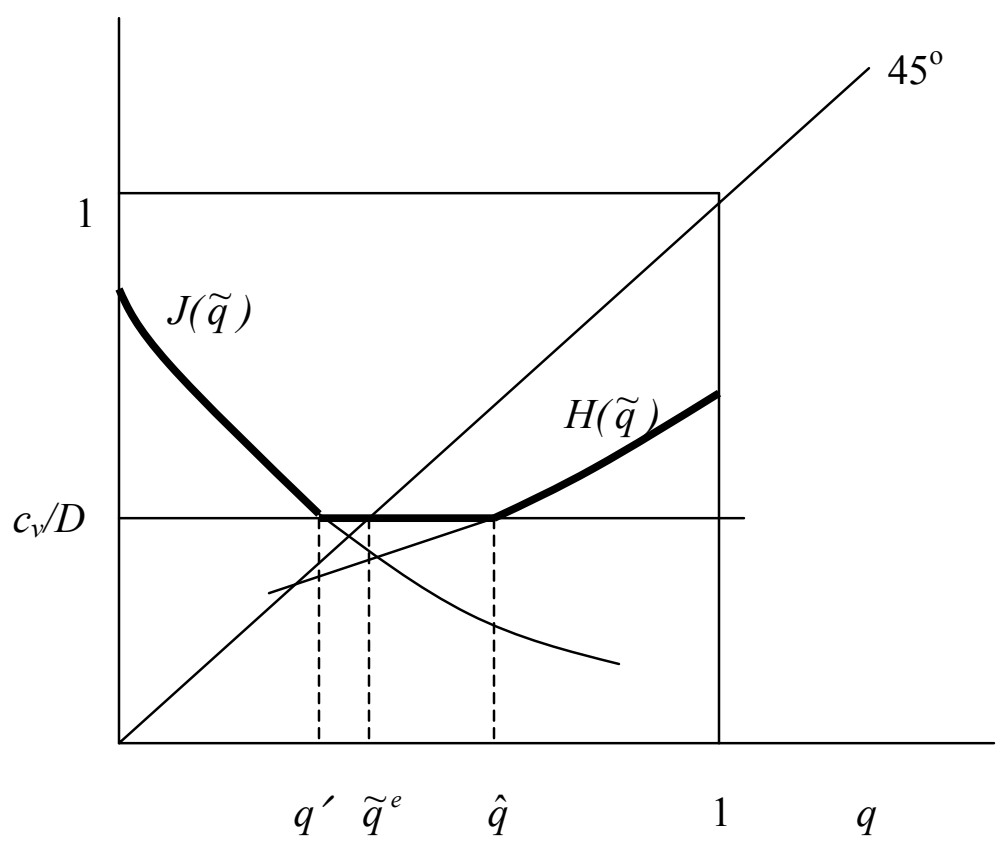

b. Bankruptcy in $\mathrm{t}=2$; zero return from illness suits. 


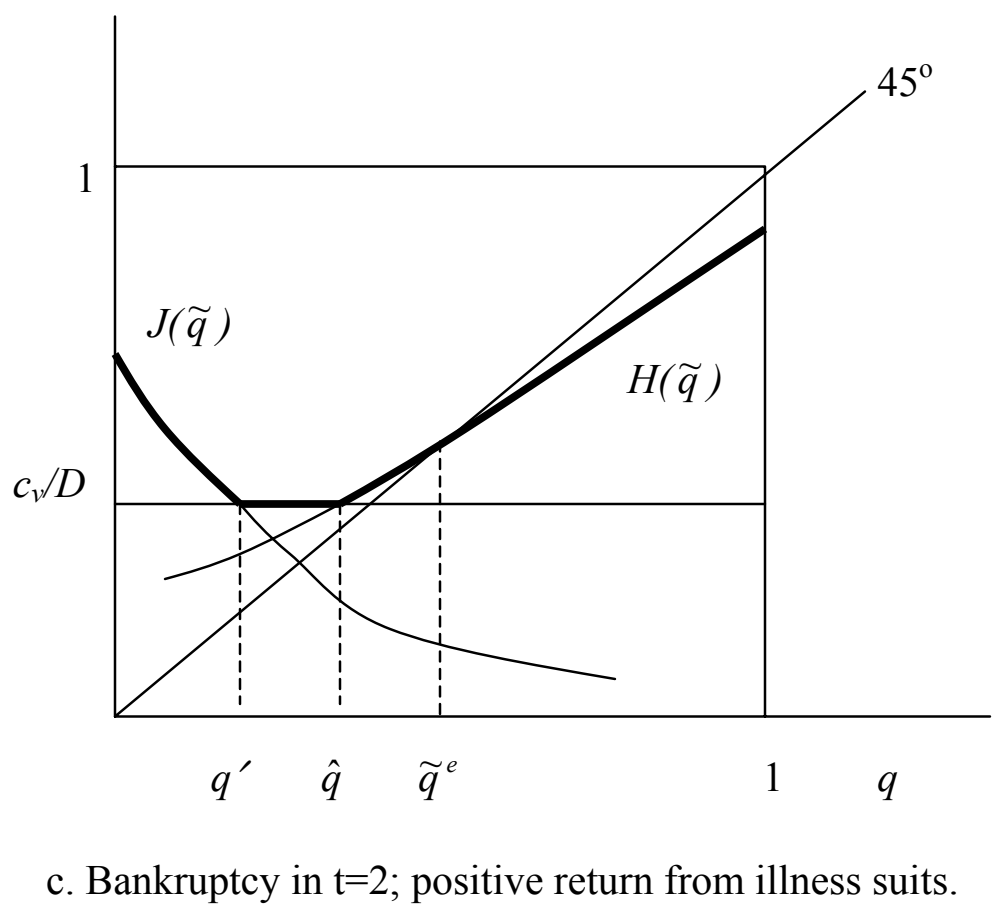

Figure 1. Possible Nash equilibria when bankruptcy is inevitable. 


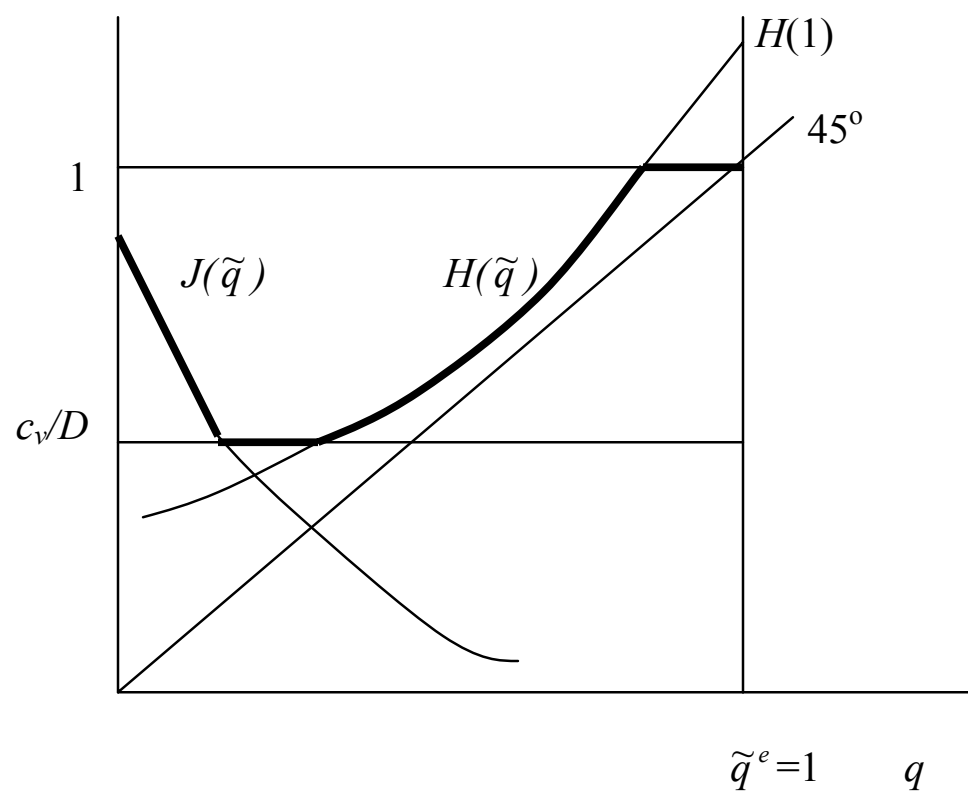

Figure 2. Unique equilibrium in which all victims wait to file.

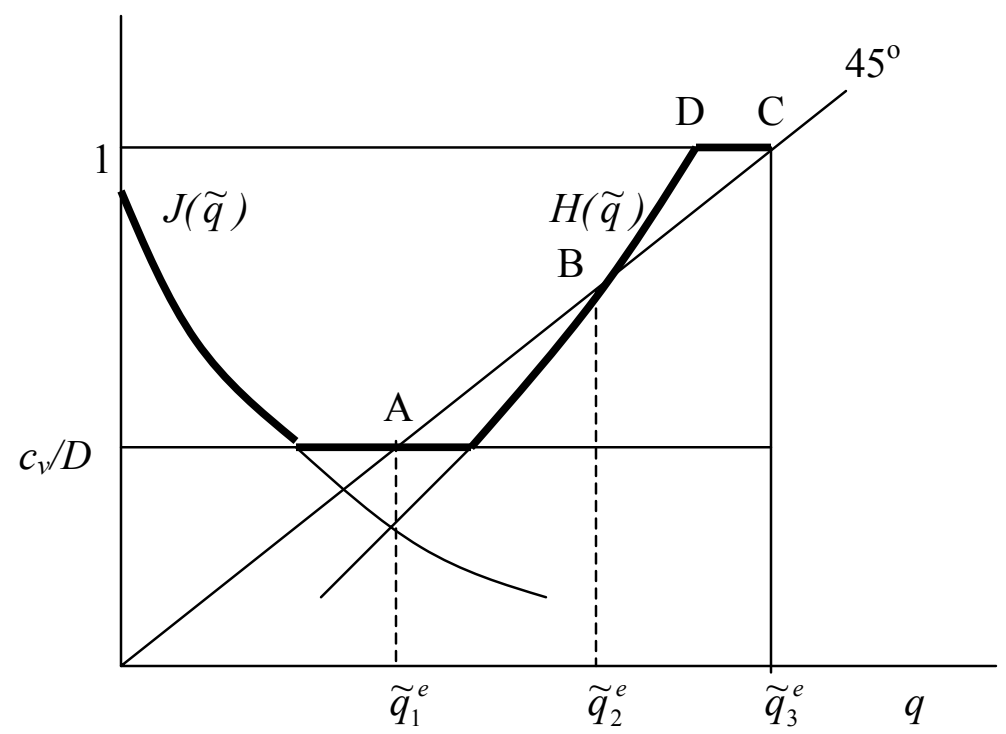

Figure 3. Multiple equilibria when bankruptcy is not inevitable. 


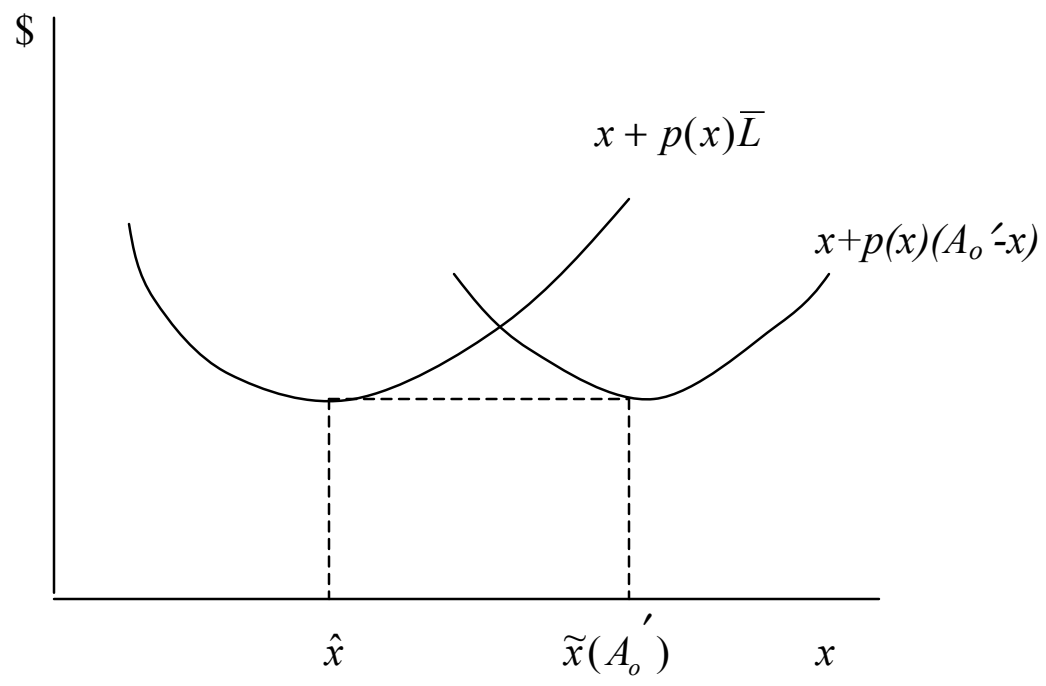

Figure 4. Optimal care choice of the injurer. 